\title{
MIGRASI BATAK DI TANAH ALAS KABUPATEN ACEH TENGGARA
}

(1904-1920)

\author{
Oleh: \\ Lister Eva \\ Rina Ariani Pandiangan
}

\begin{abstract}
ABSTRAK
Penelitian ini bertujuan untuk mengetahui latar belakang sejarah awal migrasinya batak toba ke wilayah Tanah Alas Kabupaten Aceh Tenggara (1904-1920), bagaimna proses terjadinya migrasi Batak Toba diwilayah Tanah Alas dan apa saja dampak yang terjadi pada masayrakat tanah Alas ketika kedatangan masyarakat suku Batak Toba kewilayah tersebut. Penelitian ini merupakan penelitian sejarah dengan menggunakan 4 tahap penelitian yaitu pertama, pengumpulan sumber-sumber yang relevan dengan penelitian. Dalam pengumpulan data, peneliti melakukan penelitian lapangan dengan observasi, wawancara serta untuk mendukung data penelitian juga melakukan penelitian kepustakaan dengan mengumpulkan buku-buku,dokumen, artikel dan sejenisnya. Kedua data yang dikumpilkan tersebut diuji kebenarannya lewat kritik sumber, ketiga penafsiran sumber dan yang keempat ialah pemulisan.Berdasarkan hasi penelitian yang dilakukan diketahui bahwa terjadinya Migrasi Batak Toba ke wilayah Tanah Alas disebabkan karena faktor kedatangan kolonial Belanda kewilayah tanah Batak, khususnya di daerah Sidikalang. Daerah sidikalang merupakan daerah awal datangnya migrasi Batak Toba kewilayah Tanah Alas Kabupaten Aceh Tenggara dan melarikan diri dari daerahnya sendiri menuju daerah baru dan mulai melakukan penjajakan diwilayah baru.Terjadinya migrasi Batak Toba di Tanah Alas memberikan dampak yang sangat mempengaruhi masyarakat suku Alas yaitu dengan sistem pertanian, sistem pertanian yang ditanamkan oleh masyarakat Batak Toba membantu meningkatkan perekonomian baik pada masyarakat Batak Toba itu sendiri maupun masyarakat suku Alas dengan cara mengelolah lahan-lahan yang kosong milik suku Alas menjadi lahan pertanian yang sangat subur.
\end{abstract}

Kata Kunci : Migrasi, Batak Toba dan Tanah Alas 


\section{I.PENDAHULUAN}

Migrasi pada umumnya dipengaruhi oleh beberapa faktor, tergantung pada karakteristik daerah asal,daerah tujuan dan individu yang melakukan migrasi, serta adanya perbedaan nilai, atau kenyamanan dalam suatu wilayah tersebut. Meninggalkan daerah asal kedaerah tujuan tentu disebabkan karena ada rasa ketertarikan atau keuntungan dibanding dengan daerah asal migrasi. Secara umum faktor yang mempengaruhi migrasi ialah faktor ekonomi dan non ekonomi.

Perpindahan penduduk (migrasi) yang terjadi di Indonesia sudah merupakan tradisi bagi masyrakat, perpindahan penduduk dari satu tempat ke tempat lain sudah terjadi sejak dahulu Sejak jaman manusia purba, yaitu hidup berpindah-pindah "nomaden" untuk mencari bahan makanan dan lahan yang bisa ditanamami. Perpindahan (migrasi) para pendatang dapat dikatakan sebagai gerak pindah penduduk dari satu tempat ke tempat lain dengan maksud mencari nafkah atau menetap.

Metode Penelitian yang akan digunakan oleh penelitiadalah metode sejarah. Yang diambil dari metode penelitia Helius Sjamsuddin yang terdiri dari empat tahapan dalam penelitian sejarah yaitu: (1) pengumpulan sumber (Heuristik); (2) Kritik; (3) penafsiran (Interpretasi); (4) penulisan (Historiografi). Keempat tahap tersebut akan dilaksanakan oleh peneliti untuk mengkaji tentang bagaimana Proses terjadinya Migrasi Batak Toba ke wilayah Tanah Alas Kabupaten Aceh Tenggara yang akan menyebabkan berkembangnya suku Batak Toba dan Agama Protestan diwilayah Tanah Alas Kabupaten Aceh Tenggara.

Lokasi penelitian ini dilakukan di beberapa kecamatan yang penduduknya mayoritas adaalah suku Batak Toba di Kabupaten Aceh Tenggara yaitu Kecamatan Babul Makmur, Kecamatan Lawe sigala-gala, dan Kecamatan Perkison.

Dalam meneliti tentang Sejarah Migarasi Batak Toba ke Tanah Alas Kabupaten Aceh Tenggara, peneliti mengumpulkan sumber dimana sumber tersebut terdiri atas dua jenis yaitu: 


\section{a. Sumber Primer}

Sumber ini diperoleh melalui wawancara dengan salah satu orang yang bermigrasi ke Tanah Alas pada tahun 1920. Selain itu ada salah satu bukti yang menyatakan bahwa Migrasi Batak Toba Ketanah Alas Bersamaan dengan masukinya agama kristen di tanah alas dibuktikan dengan bagunan gereja yang dibagun oleh masyarakat batak toba pada tahun 1934.

b. Sumber sekunder

Dalam penelitian ini yang menjadi data sekunder adalah data yang diperoleh dari dokumen tertulis, yakni melakukan pengkajian terhadap buku-buku yang berkaitan dengan penelitian. Selain itu, data-data tertulis tersebut juga didukung dengan data yang yang diperoleh melalui wawancara dengan masyarakat yang mengetahui peristiwa migrasi Batak Toba ke Tanah Alas.

\section{II.PEMBAHASAN}

Dalam Buku Jongejans (2008:65) menyatakan bahwa kedatangan suku batak toba ke wilayah Tanah Alas berasal dari Tanah Batak atau sekitaran wilayah danau toba, pemukiman pertama orang batak Toba yang melakukan migrasi tersebut berada di wilayah Batu Mbulan dan di Tanoh Alas. Jalur migrasi yang dilewati oleh suku Batak Toba ialah melalui jalur jalan sempit yaitu Tanah Batak-sidikalang-kutebuluhlau Baleng-Gajah Mati- Salim Pipit dan sampai ke wilayah Mbatu Bulan. Wilayah Mbatu Bulan ini merupakan wilayah pertama bermukimnya suku Batak Toba diwilayah Tanah Alas dengan beberapa orang untuk melihat kondisi wilayah yang akan mereka datangi yaitu marga Panjaitan menikah dengan boru simanjuntak dengan keturunan 4 orang anak, 2 laki-laki dan 2 perempuan, Sihotang menikah dengan Naibaho ,Simatupangdengan boru hutajulu,Sinaga menikah dengan boru siregar dan Simbolon menikah dengan boru sihombing jadi merekalah merupakan orang yang pertama melihat Tanah Alas yang pada saat itu mereka merupakan orang yang bekerja dalam pembuatan jembatan milik Kolonial Belanda. 
Hal serupa dengan pernyataan Tanjung dalam buku Dairi dalam kilatan sejarah (2010:25-26) menyatakan migrasi yang terjadi diTanah Alas bisa dikatakan bersifat alami, karena kedekatan jarak antara sidikalang dengan daerah Tanah Alas yang merangsang interaksi lebih merupakan pemicunya terjadinya migrasi. Pada tahun 1883, kolonial belanda memutuskan untuk memerangi Sisingamagaraja XII yang berdiam di Paya Raja, Dairi, sehingga pada tahun 1904-1905 melangsungkan ekspedisi kedua untuk menguasai wilayah sidikalang dan pada saat itulah banyak masyarakat Batak Toba melarikan diri kehutan dan mulai memasuki wilayah-wilayah baru seperti bagian Utara Tanah Alas, bagian selatan Salak (PakPak) dan Barat Aceh Selatan.

Hasil wawancara langsung dengan salah satu narasumber warga dari Lawe Alas Sabudin Siregar (21-05-2018), ketika Kolonial Belanda memasuki wilayah Tanah Batak dan hampir menguasai seluruh wilayah Tanah Batak sampai ke daerah Dairi (Sidikalang) banyak masyarakat Batak Toba dijadikan oleh Kolonial Belanda jadi Budak dan para pekerja Paksa di perkebunan dan ladang Kolonial Belanda dimana kekejaman Belanda dengan sistem pemerasan dan sistem tanam paksa yang dilakukan agar masyarakat Batak toba mau menanam Kopi,Jati,kemiri dan rempah-rempah lainnya pada saat itu yang membaut banyak masyarakat Batak Toba mulai tidak nyaman tinggal diwilayah mereka sendiri, sehingga banyak masyarakat atau suku Batak Toba yang melarikan diri ketika malam hari, alasan mereka melakukannya pada malam hari adalah agar mereka yang mencoba melarikan diri tidak ketahuan oleh Belanda sama seperti sebelumnya ketika mereka melarikan diri pada siang harinya. Batak Toba yang melarikan diri tersebut tidak mengetahui Tujuan dan Arah mereka melarikan diri, hal yang paling penting adalah bagaimana caranya agar mereka bebas dari kekuasaan Belanda pada saat itu, sehingga banyak suku batak toba yang menyebar diberbagai daerah seperti daerah kita ini Tanah Alas.

Pada masa Kolonial Belanda banyak orang Batak pindah dari Daerah Dairi (Sidikalang) ke daerah Tanah Alas, sebagian kecil ada yang Singkil (Aceh Selatan). Dibeberapa daerah di Tanah Alas dilanda oleh migrasi Batak Toba yang pertama adalah 
berada di daerah Mbatu Bulan. Dearah Mbatu Bulan ini dalah merupakan Daerah awal migrasi Batak Toba dari wilayah Tanah Batak ke wilayah baru yaitu wilayah Tanah Alas dan membuka perkampungan disana dengan meminta persetujuan kepala suku daerah tersebut, karena rasa yang sepenanggungan oleh Kolonial maka kepala suku Tanah Alas menerima suku Batak Toba untuk tinggal disana dan memberikan lahan pertanian untuk dikerjakan oleh masyarakat Batak Toba tersebut.

Dalam bukunyaO.H.S Purba dan Elvis F. Purba (1998:35) yang berjudul "Migran Batak Toba di Luar Tapanuli Utara: suatu deskripsi”, menjelaskan bahwa perpindahan orangBatak Toba ke berbagai daerah khususnya daerah kabupaten Dairi sudah terjadi sejakdahulu. Perpindahan orang Batak Toba ke daerah Dairi/Sidikalang sudah terjadi sejakpermulaan tahun 1900-an. Ada dua hal penyebab orang-orang Tapanuli memasukiDairi, kehadiran kolonial Belanda di tanah Batak dan usaha missioner Jerman yangingin memperluas daerah kerjanya.

Kedatangan orang Batak Toba ke Sidikalang semakin banyak bertambah dari tahun ke tahun. Kehadiran orang Batak Toba didaerah Sidikalang membawa beberapa dampak khususnya perkembangan Sidikalang menjadi sebuah perkampungan yang ramai. Orang Batak Toba yang datang ke Dairi membuka kampung-kampung baru sebagai tempat tinggal mereka. Karena kebanyakan orang Batak Toba yang datang ingin menetap di daerah perantauan.Yaitu dengan mendirikan rumah-rumah sederhana di ladang-ladang mereka tinggali.Perubahan lainnya adalah berkembangnya agama Kristen yang dibawa oleh parapedagang Batak Toba. Orang Batak Toba yang datang ke daerah Sidikalang juga mengadakan penginjilan.

Penyebaran agama Kristen di Tanah Pakpak pada awalnya tidak diterima karena sebelumnya sudah berkembang agama Islam, sehingga penyebaran agama Kristen dianggap kafir. Lama kelamaan masyarakat setempa tmulai menerima menjadi suatu agama baru. Kedatangan orang Batak Toba juga disebabkan oleh pembukaan jalan yang membuat orang Batak Toba semakin mudah untuk melakukan perpindahan ke daerah lain. Sidikalang juga menjadi daerah transit pendatang-pendatang baru dari 
Toba Holbung, Humbang, Silindung untuk meneruskan perjalanan ke daerah lain seperti ke Tanah Alas dan Singkil.

Beberapa tahun kemudian dilakukan lagi pembukaan jalan dari kabanjahe ke Kutacane dan jalan kesidikalang. Friderich sibarani (berasal dari Laguboti Tapanuli Utara) dan kawan kawannya bekerja di bidang jembatan dan bangunan-bangunan lainnya, akhirnya sampai ke Bambel. Mereka ditugaskan dalam bidang pertukangan dan perbaikan jembatan dilingkungan kejuren Bambel. Setelah beberapa lama disana, akhirnya memasuki Pulo Nas (Tahun 1819) dan Sibarani beserta keluarga tinggal menetap dan membuka pertukangan di Titi Panjang. Kemudian hari, keluarga ini menjadi tempat tinggal sementara dan sumber informasi penting bagi pendatang baru dari Tanah Batak yang sampai ke Titi Panjang., lalu ada beberapa masyarakat Batak Toba yang pulang untuk menjemput isterinya dan keluarganya untuk bermigrasi diwilayah Tanah Alas, sehingga menyebar keberbagai daerah ditanah Alas seperti di Pulo Nas, Bunga Melur,Kuning, Lawe Pertanduk dan wilayah Lawe Sigala-gala.

Hasil wawancara dengan narasumber (10-06-2018), warga Tanoh Alas dengan Tamaria Panjaitan (Op.Susi) yang merupakan orang yang ikut melakukan Migrasi dari Tanah Batak ke Wilayah Tanah Alas. Motif migrasinya Orang Tua dari Op. Susi tersebut ialah karena motif Kolonial Belanda, dimana pada waktu kedatangan Belanda ke Tanah Batak (Samosir) membuat keluarga Op. Susi menjadi pe kerja paksa dan melakukan kekerasan pada masyarakat Batak Toba jika tidak ikut menjadi pekerja.. Kerja paksa yang dilakukan oleh Belanda ialah membuat masyarakat Suku Batak Toba yang awalnya bertani dipaksa untuk menanam tanaman seperti Kopi,Tembakau dan lainnya di wialyah lahan pertanian mereka Dan pada saat itu Ayah dari Op. Susi ini dibawa oleh Belanda untuk membangun sebuah jembatan atau jalan dari Tanah Karo (Kabanjahe) ke wilayah Tanah Alas (Kutacane) dan dengan informasi yang didapat ada wilayah baru yang belum diketahui oleh banyak orang sehingga pada saat itu Ayah dari Op. Susi tersebut berniat untuk melakukan penjajakan ke wilayah Tanah Alas tersebut dan berniat untuk menetap dan membuka lahan pertanian diwilayah Tanah Alas taanpa harus diketahui oleh kolonial belanda dan bertahan agar terbebas dari kekejaman 
Belanda pada saat itu dan hal yang sangat menarik yang dapat diambil dari wawancara tersebut adalah Lagu yang dibuat tanpa sengaja dan dinyanyikan oleh masyarakat Batak Toba sepanjang perjalanan menuju wilayah baru yang akan mereka dapat dan temui.Op. Susi mengatakan lagu ini merupakan lagu yang sangat tidak terkenal atau bahkan tidak ada yang mengetahuinya kecuali mereka yang ikut melakukan migrasi pada saat itu juga atau keturunan dari mereka yang ikut melakukan penjajakanpenjajakan wilayah-wilayah baru yang akan mereka tuju.

Tung haccit ma hape sitaonon

Dung dirajai si Bontar mata

Bangsa indonesia on

Asa lam tu met met na

Dirohana indonesia

Sai tontong

Ari walu sada sia sada opat

Ai tung haccit ma

Sitaonon dung dipalaao sibontar mata

\section{Artinya :}

Begitu sakit rasa yang kupikul

Setelah dikuasai oleh Belanda

Bangsa indonesia ini

Biar semakin mudah dan kecil

Didalam hatinya bangsa indonesia ini

Hari kedelapan satu sembilan satu empat

Semakin sakitlah

Yang yang dirasakan setelah diusir oelh

Kolonial Belanda

Tabel 4.2

Tahap Migrasi Batak Toba ke wilayah Tanah Alas

\begin{tabular}{|c|c|c|c|c|}
\hline $\begin{array}{c}\text { Tahap } \\
\text { Migrasi }\end{array}$ & $\begin{array}{l}\text { Jumlah } \\
\text { Migrasi }\end{array}$ & $\begin{array}{c}\text { Latar } \\
\text { Belakang }\end{array}$ & Tujuan & Hasil Migrasi \\
\hline $\begin{array}{c}\text { Tahap } \\
1\end{array}$ & $\begin{array}{c}5 \\
\text { Orang }\end{array}$ & $\begin{array}{l}\text { Untuk } \\
\text { menghidari } \\
\text { Kolonial } \\
\text { Belanda } \\
\text { pada saat itu } \\
\text { yang } \\
\text { dimana }\end{array}$ & $\begin{array}{l}\text { Untuk melihat kondisi } \\
\text { awal wilayah Tanah } \\
\text { Alas sebelum } \\
\text { melakukan migrasi } \\
\text { dengan masyarakat } \\
\text { suku Batak lainnya. }\end{array}$ & $\begin{array}{l}\text { Hasilnya } \\
\text { mayarakat Batak } \\
\text { Toba yang } \\
\text { melihat wilayah } \\
\text { Tanah Alas } \\
\text { sangat } \\
\text { menguntungkan }\end{array}$ \\
\hline
\end{tabular}




\begin{tabular}{|c|c|c|c|c|}
\hline & & $\begin{array}{l}\text { banyak } \\
\text { masyarakat } \\
\text { Batak Toba } \\
\text { dijadikan } \\
\text { pekerja } \\
\text { paksa dalam } \\
\text { penanaman } \\
\text { tanaman } \\
\text { baru yaitu } \\
\text { Kopi, } \\
\text { Kemiri dan } \\
\text { coklat. }\end{array}$ & & $\begin{array}{l}\text { dibandingkan } \\
\text { dengan wilayah } \\
\text { daerah asal } \\
\text { mereka karena } \\
\text { wilayah Tanah } \\
\text { Alas yang sangat } \\
\text { Luas dan subur } \\
\text { dapat membantu } \\
\text { masyaraklat } \\
\text { batak toba yang } \\
\text { akan mel;akukan } \\
\text { migrasi } \\
\text { kemudian } \\
\text { mendatang }\end{array}$ \\
\hline Tahap 2 & $\begin{array}{l}1.109 \\
\text { orang }\end{array}$ & $\begin{array}{l}\text { Untuk } \\
\text { menghidari } \\
\text { Kolonial } \\
\text { Belanda } \\
\text { pada saat itu } \\
\text { yang } \\
\text { dimana } \\
\text { banyak } \\
\text { masyarakat } \\
\text { Batak Toba } \\
\text { dijadikan } \\
\text { pekerja } \\
\text { paksa dalam } \\
\text { penanaman } \\
\text { tanaman } \\
\text { baru yaitu } \\
\text { Kopi, } \\
\text { Kemiri dan } \\
\text { pohon jati }\end{array}$ & $\begin{array}{l}\text { 1. Mencari wilayah } \\
\text { baru yang belum } \\
\text { di jajak oleh } \\
\text { banyak orang dan } \\
\text { untuk memulai } \\
\text { kehidupan yang } \\
\text { baru ditempat } \\
\text { yang baru. } \\
\text { Kehabisan lahan } \\
\text {,dan jumlah } \\
\text { penduduk yang } \\
\text { semakin banyak } \\
\text { dibanding dengan } \\
\text { lahan yang } \\
\text { semakin sempit. } \\
\text { karena pada saat } \\
\text { itu lahan-lahan } \\
\text { dari masyarakat } \\
\text { batak toba hampir } \\
\text { dikuasai oleh } \\
\text { kolonial belanda } \\
\text { dan lahan mereka } \\
\text { disewakan } \\
\text { belanda kepada } \\
\text { mereka dengan } \\
\text { menggunakan } \\
\text { mereka sebagai }\end{array}$ & $\begin{array}{l}\text { 1. Mereka } \\
\text { diterima } \\
\text { diwilayah tanah } \\
\text { alas karena } \\
\text { alasan adanya } \\
\text { rasa depenganggunga } \\
\text { sepalam } \\
\text { menentang } \\
\text { kolonial } \\
\text { belanda. } \\
\text { 2. Adanya ikatan } \\
\text { persaudraan } \\
\text { antara Raja } \\
\text { Lambing dengan } \\
\text { Raja } \\
\text { Sisinganmagaraj } \\
\text { a XII. } \\
\text { 3. Banyak } \\
\text { masyarakat } \\
\text { Batak Toba yang } \\
\text { tinggal dan } \\
\text { menetap } \\
\text { diwilayah Tanah } \\
\text { Alas dengan } \\
\text { pekerjaan yaitu } \\
\text { menjadi Pekerja } \\
\text { Ladang }\end{array}$ \\
\hline
\end{tabular}




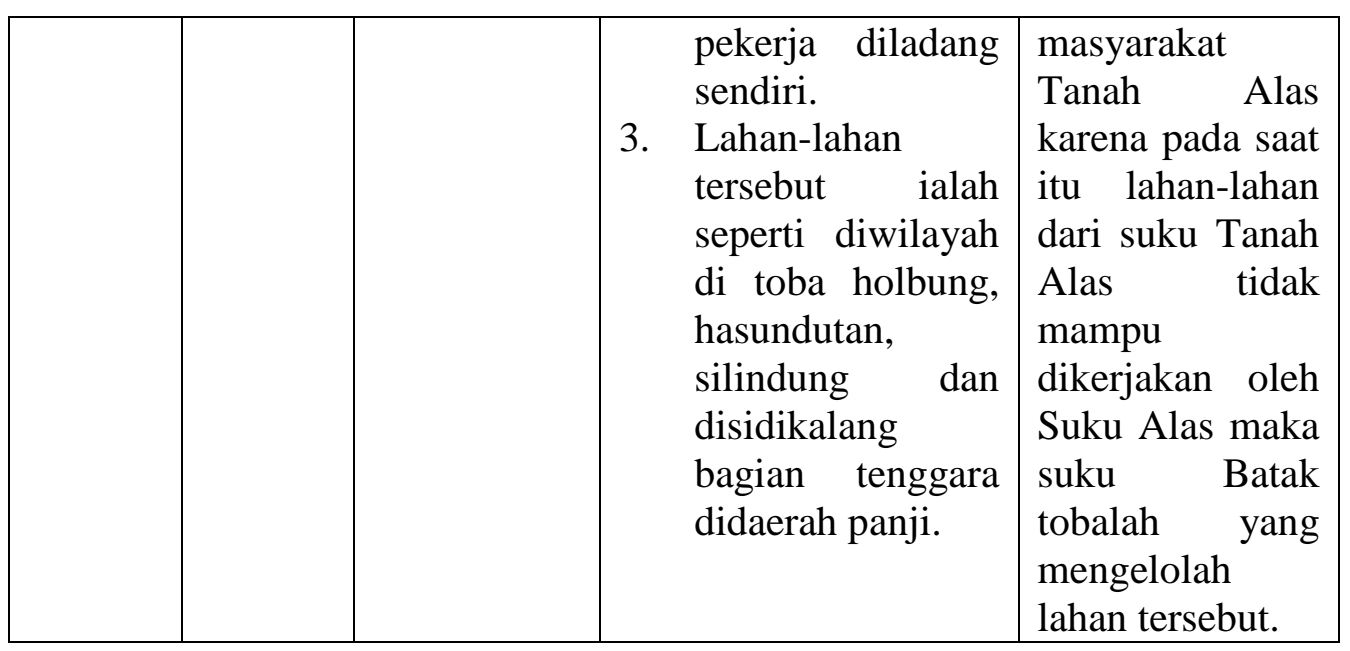

Dalam Buku Mohammad Said (1961) yang berjudul "Aceh Sepanjang Abad" Salah satu faktor lainnya yang menyebutkan migrasi Batak Toba ke Tanah Alas ialah ketika dibukanya jalan ke Gayo yang menjadi salah satu faktor kedatangan Belanda untuk melancarkan penyerangan kedaerah Gayo, Tapanuli dan Alas oleh Van Daalen yang diberi nama "Gayo-tocht" ia melakukan penyerangan ke kampung-kampung sepanjang jalan antara Takengon sampai ke wilayah Sidikalang, terutama kampung Kutacane dan Kuta Reh yang berada di wilayah Tanah Alas.

Hasil wawancara yang dilakukan dengan salah satu narasumber di desa lawe Alas yaitu dengan Bapak Jumadin Sinaga (28-05-2018), bapak Jumadin merupakan kepala Desa Lawe Alas. Motif kedatangan Kolonial Belanda ke wilayah Tanah Alas ialah ketika pada saat itu wilayah Tanah Batak sudah dikuasai oleh Kolonial Belanda dan Belanda pada saat itu ingin menguasai wilayah-wilayah lainnya termaksud wilayah Tanah Alas,. Jadi banyak masyarakat suku Batak Toba yang melarikan diri keberbagai wilayah seperti Kabnjahe, Singkil,Gayo dan Tanah Alas, suku Batak Toba yang melakukan Migrasi Tersebut menggunakan Jalur Hutan Rimba dengan Melewati Tanah Karo-Kutabuluh-Lau Baleng-Gajah Mati-Salim Pipit-Tanoh Alas. Wilayah pertama yang menjadi Migrasinya Batak Toba ialah berada di daerah Mbatu Bulan. Konon katanya Mbatu Bulan dikuasai oleh seorang Raja yaitu Raja Lambing yang merupakan Rumpun dari raja Lotung (Marga Batak), sehingga orang Batak Toba yang 
datang kewilayah Tanah Alas tersebut diterima dengan baik karena ada rasa Dalihan $\mathrm{Na}$ Tolu (kekeluargaan) dan rasa sepenanggungan dari Kolonial Belanda. Diterimanya masyarakat Batak Toba diwilayah tersebut dengan syarat mereka akan dijadikan sebagai Petani yang bekerja pada masyarakat Tanah Alas dan mengelolah lahan-lahan kosong untuk ditanami dan masyarakat Batak Toba juga Pandai membuat Besi (pembuat Parang, Pisau), karena orang batak pendatang tersebut sudah pandai bertani dan membuat besi, jadi orang Batak Toba diwilayah Tanoh Alas dijuluki dengan Pandai Besi dan para pekerja ladang pada saat itu.

Sesuai dengan pernyataan Sangti (1997:198) dalam Buku yang berjudul "Sejarah Batak" menjelaskan bahwa sejak tahun1920-an banyak penduduk suku Batak Toba pindah ke Tanah Alas dengan membuka lahan persawahan, dimana pada awalnya disambut baik oleh masyarakat Tanah Alas, diantaranya karena adanya ikatan kekeluargaan dan kebudayaan Dalihan $\mathrm{Na}$ Tolu serta adanya rasa sepenanggugan dalam menentang kolonialisme Belanda.

Sistem cara kerja masyarakat Batak Toba ketika sudah melakukan migrasi kewilayah Tanah Alas. Pada awalnya satu kelompok masyarakat Batak Toba hanya mendapatkan lahan seluas $0,5 \mathrm{Km}^{2}$. Apabila mereka berhasil menjadikan areal pertanian dan bermaksud menetap. Permohonan untuk memperoleh lahan yang lebih luas, jika lahan yang diterima dirasa masih sempit dapat diajukan kepada penguasa atau kepada kejuren. Jerih payah masyarakat Batak Toba untuk membuka persawahan memang terbukti dan ingin tetap tinggal menetap disana dengan syarat yang mereka sepakati ialah masyarakat Batak Toba akan meninggalkan wilayah Batak Toba apabila mereka diislamkan O.H.S Purba dan Elvis F. Purba (1997:142-145) 


\section{PENUTUP}

Migrasi memliki makna yang berbeda-beda bagi setiap suku bangsa, bagi suku Batak Toba sendiri migrasi adalah perpindahan dari kampung asalnya kedaerah migrasinya wilayah lain yang lebih menjamin kehidupan lebih baik yang dimotivasi oleh 3H yaitu Hagabeon, Hamoraoan dan Hasangapon. Migrasi Batak Toba adalah marserak, kenapa Marserak? Karena mereka suku Batak Toba yang telah melakukan migrasi akan jarang kembali kedaerah asal, tetapi mereka akan memilih tetap tinggal didaerah mana mereka mendapatkan kehidupan yang lebih baik.

Adapun faktor-faktor yang mendorong proses Migrasi Batak Toba dari Tanah Batak ke wilayah Tanah Alas yaitu :

1. Kedatangan Kolonial Belanda ketanah Batak menyebabkan migrasi secara tidak langsung pada masyarakat suku Batak Toba dimana pada saat itu adanya sistem Tanam Paksa pyang dilakukan oleh Kolonial Belanda pada masyarakat Batak Toba diwilayah Tanah Batak.

2. Usaha kolonial Belanda karena kebutuhan tenaga kerja pada perusahaanperusahan yang mereka buka, selain itu juga mereka bekerja untuk memenuhi kebutuhan para kolonial belanda.

3. Lokasi atau letak wilayah Tanah Alas sangat Strategis dan Tanah yang sangat subur, menjadi salah satu faktor migrasinya Batak Toba kedua dalam jumlah besar dan memilih untuk tetap tinggal diwilayah tersebut, karena Tanah yang subur menjamin kehidupan yang lebih baik lagi.

4. Usaha orang tapanuli untuk mencari lahan pertanian baru, karena faktor keterbatasan lahan yang tidak subur dan sempit diwilyah Tanah Batak dan sekaligus karena kesuburan alam diwilayah Tanah Alas dan masih banyak lahan-lahan kosong yang belum dijajak oleh orang yang menyebabkan suku Batak Toba melakukan Migrasi secara tidak langsung dan langsung kedaerah tersebut. 
5. Perpadatan penduduk yang menjadi salah satu faktor menyebabkan adanya perpindahan penduduk dari daratan yang tinggi kedaratan yang rendah dengan tujuan untuk mencapai kehidupan yang lebih baik.

6. Dengan adanya Migrasi Batak Toba diwilayah yang baru khusunya Tanah Alas sangat membantu kehidupan sehari-hari pada masyarakat suku Alas dan menambah pengeetahuan tentang pertanian.

Dengan beberapa faktor-faktor terjadinya proses migrasi Batak Toba kewilayah Tanah Alas, maka dapat kita simpulkan bahwa faktor atau alasan yang menjadi sangat khusu migrasi suku Batak Toba kewilayah Tanah Alas adalah karena kedatangan kolonial belanda kewilayah Tanah Batak yang membuat banyak masyarakat Batak Toba melarikan diri keberbagai wilayah dan menemukan wilayah Baru untuk memenuhi kebuthan sehari dan memenuhi filosopi yang selalu dibawa yaitu $3 \mathrm{H}$, Hagabeon, Hamoraon dan Hasangapon. 


\section{Daftar Referensi}

Butilan,Ompu (1971)." "Suku Bangsa Batak Toba Sedjak Abad ke XIV”.Koran.

Daliman. 2012. "Metode Penelitian Sejarah”. Yogyakarta: Ombak

Dinas Kebudayaan dan Parawisata Kabupaten Aceh Tenggara.(2013) "Adat Perkawinan dan Sunat Rasul Suku Alas Kabupaten Aceh Tenggara”.kutacane

Koentjaranigrat.(2011). "Pengantar Antropologi I".Jakarta : Rineka Cipta

Limbong,Mesrida.(2010). "Migrasi Orang Batak Toba Di Sidikalang (19641985”).Skripsi.Usu

Purba,O.H.S \& Purba,Elvis.F.(1997), “Migran Batak Toba Di Luar

Tapanuli Utara: Suatu Deskripsi.Medan : Monora

Purba,O.H.S \& Purba,Elvis.F.(1997), "Migrasi Spontan Batak Toba:

Sebab,Motif dan Akibat Perpindahan Penduduk dari Daratan Tinggi Toba.

Medan : Monora.

Pelly,Usman(1994). “Urbanisasi dan Adaptasi”.Jakarta:PT Pustaka LP3ES

Reid,Anthony.(2011).“Menuju Sejarah Sumatera antara Indonesia dan

Dunia”.Jakarta:YOI

Sangti,Batara.(1977).“Sejarah Batak”.Balige.

Said,Mohammad.(1961). “Aceh Sepanjang Abad”.Medan: PT Harian Waspada.

Simanjuntak,Bungaran.(2004)“Arti dan Fungsi Tanah Bagi Masyarakat Batak. Medan : Badan Pengurus KSPPM.

Simanjuntak,Bungaran.(2011)“Konflik Status dan Kekuasaan Orang Batak Toba”.Jakarta:YOI

Sinaga,Anicetus.(2014)“Allah Tinggi Batak-Toba: Transendensi dan Imanensi”. Yogyakarta : PT Kanisius

Sjamsuddin, Helius. 2012. “Metodologi Sejarah”. Yogyakarta: Ombak

Simanjuntak,Bungaran.(2015) “Arti dan Fungsi Tanah bagi Masyarakat Batak Toba, Karo,Simalungun.Jakarta:YOI

Silalahi,dkk.(2013).Migrasi Suku Batak Toba Asal Tapanuli Utara (Sumatera Utara) 1965-1975 kekelurahan Bandarjaya Timur kecamatan Terbanggi Besar kabupaten lampung tengah. Volume 1. 6 Halaman.

Safitri,dkk.(2013).Jaringan Sosial dan Strategi Adabtasi Asal Lampung di Desa Jayamukti. kecamatan Cikarang Pusat. Kabupaten Bekasi. Provinsi Jawa Barat.Sodality. Volume 1.14 Halaman.

Tanjung,Flores.2010. "Dairi Dalam Kilatan Sejarah”. Bandung : Alfabeta 